\title{
Assessing the molecular divergence between Anopheles (Kerteszia) cruzii populations from Brazil using the timeless gene: further evidence of a species complex \\ Luísa DP Rona1, Carlos J Carvalho-Pinto ${ }^{2}$, Carla Gentile ${ }^{1,3}$, Edmundo C Grisard ${ }^{2}$ and Alexandre A Peixoto*1
}

\begin{abstract}
Address: ${ }^{2}$ Laboratório de Biologia Molecular de Insetos, Instituto Oswaldo Cruz, FIOCRUZ, Av. Brasil 4365, Rio de Janeiro 21045-900, RJ, Brazil, ${ }^{2}$ Departamento de Microbiologia e Parasitologia, CCB, Universidade Federal de Santa Catarina, Florianópolis 88040-970, SC, Brazil and ${ }^{3}$ School of Biological and Chemical Sciences, Queen Mary University of London, 327 Mile End Road, London, E1 4NS, UK
\end{abstract}

Email: Luísa DP Rona - luisadrp@ioc.fiocruz.br; Carlos J Carvalho-Pinto - carlospinto@ccb.ufsc.br; Carla Gentile - c.gentile@qmul.ac.uk; Edmundo C Grisard - grisard@ccb.ufsc.br; Alexandre A Peixoto* - apeixoto@ioc.fiocruz.br

* Corresponding author

Published: 9 April 2009

Malaria Journal 2009, 8:60 doi:10.1/86/1475-2875-8-60

This article is available from: http://www.malariajournal.com/content/8/I/60

(C) 2009 Rona et al; licensee BioMed Central Ltd.

This is an Open Access article distributed under the terms of the Creative Commons Attribution License (http://creativecommons.org/licenses/by/2.0), which permits unrestricted use, distribution, and reproduction in any medium, provided the original work is properly cited.
Received: 24 November 2008

Accepted: 9 April 2009

\begin{abstract}
Background: Anopheles (Kerteszia) cruzii was the most important vector of human malaria in southern Brazil between 1930-1960. Nowadays it is still considered an important Plasmodium spp. vector in southern and south-eastern Brazil, incriminated for oligosymptomatic malaria. Previous studies based on the analysis of $X$ chromosome banding patterns and inversion frequencies in $A n$. cruzii populations from these areas have suggested the occurrence of three sibling species. In contrast, two genetically distinct groups among An. cruzii populations from south/south-east and north-east Brazil have been revealed by isoenzyme analysis. Therefore, An. cruzii remains unclear.

Methods: In this study, a partial sequence of the timeless gene ( $400 \mathrm{bp})$, a locus involved in the control of circadian rhythms, was used as a molecular marker to assess the genetic differentiation between An. cruzii populations from six geographically distinct areas of Brazil.

Results: The timeless gene revealed that An. cruzii from Itaparica Island, Bahia State (north-east Brazil), constitutes a highly differentiated group compared with the other five populations from south and south-east Brazil. In addition, significant genetic differences were also observed among some of the latter populations.

Conclusion: Analysis of the genetic differentiation in the timeless gene among An. cruzii populations from different areas of Brazil indicated that this malaria vector is a complex of at least two cryptic species. The data also suggest that further work might support the occurrence of other siblings within this complex in Brazil.
\end{abstract}

\section{Background}

Anopheles cruzii is one of the few mosquito species belonging to the subgenus Kerteszia. Immature stages of this species are found associated with water trapped in the interfoliar space of plants from the Bromeliaceae family, which are abundant in the Brazilian Atlantic forest [1-3]. Accordingly, the distribution of these bromeliad-breeding mosquitoes is restricted to the Atlantic forest, which 
stretches from the coast of Rio Grande do Sul State (southern Brazil) to Sergipe State (north-eastern Brazil) $[4,5]$.

The adults are found in a variety of habitats, from sea level in coastal areas to the mountains. Females are strongly anthropophilic and preferably bite during the evening $[2,6,7]$, perhaps biting more than one host to complete egg maturation, which is epidemiologically relevant for malaria transmission [8-10].

Between 1930 and 1960, An. cruzii together with Anopheles bellator and Anopheles homunculus, which also belong to Kerteszia, were considered the main vectors of malaria when the disease was endemic in southern Brazil. Vector control measures have significantly reduced or even interrupted malaria transmission in some areas, but eradication of the pathogen was not achieved and An. cruzii is still responsible for several oligosymptomatic malaria cases in southern and south-eastern Brazil.

The Amazon region is highly endemic for human malaria, caused by Plasmodium vivax and Plasmodium falciparum, and imported cases are frequently reported in different states due to emigration from this region $[11,12]$. However, several autochthonous cases were reported in a study in Santa Catarina State, southern Brazil [12]. In the states of São Paulo and Rio de Janeiro, as well as in the state of Bahia, where An. cruzii and Anopheles (Nyssorhynchus) spp. are considered the main vectors of the disease, respectively $[3,7,13,14]$, several imported and autochthonous cases of malaria are reported every year in the Atlantic forest region [15]. Reinforcing the epidemiological importance of An. cruzii as a malaria vector in south-east Brazil, another recent study in Espírito Santo State, including the locality of Santa Teresa, suggested that this species is the potential vector of recent autochthonous cases of malaria in this state [16].

Anopheles cruzii is also a natural vector of simian malaria in Rio de Janeiro and São Paulo States [17]. Studies on seasonal and vertical distribution of An. cruzii in coastal São Paulo State demonstrated high vertical mobility from ground level to tree tops, with significantly more activity in the uppermost branch layer of the forest [18]. This behaviour could be responsible for human infection by simian Plasmodium species $[19,20]$.

Epidemiological surveillance and the use of control measures are required to avoid the expansion or introduction of malaria in areas where vector species are abundant and susceptible humans are present. Thus, assessment of the epidemiological status of such localities as well as knowledge concerning the biology, behaviour and the genetic characteristics of the vector species are relevant to prevent the occurrence of outbreaks or to lead control strategies, especially in formerly endemic areas.

Despite its epidemiological importance, there are only a few population genetic studies of An. cruzii $[18,21]$, and its taxonomic status is unclear. Anopheles cruzii is polymorphic for chromosome rearrangements. Differences in inversions frequencies, and $X$ chromosome banding patterns from south-eastern and southern Brazil, have suggested the existence of three sibling species [21-24]. On the other hand, isoenzymes indicated two genetically isolated groups, one from Bahia State (north-eastern Brazil), and the other from south-eastern and southern Brazil (Rio de Janeiro, São Paulo and Santa Catarina States) [25]. Finally, in a recent study based on sequence analysis of the second Internal Transcribed Spacer of the nuclear ribosomal DNA (ITS2), the authors found no conclusive evidence for sibling species among samples of An. cruzii from south-eastern and southern Brazilian localities [26].

The activity and feeding rhythms of insect vectors are very important to disease transmission. These patterns are controlled by endogenous circadian clocks, which are under genetic control [27]. Furthermore, clock genes are also involved in the control of mating rhythms that are potentially important in maintaining sexual isolation between closely related species $[28,29]$.

The circadian rhythms of malaria vectors belonging to the subgenus Kerteszia were formerly studied by Pittendrigh [30] and, recently, these rhythms were also studied in An. cruzii [31]. The timeless gene is involved in the control of activity rhythms in Drosophila [27], and controls differences in mating rhythms between closely related Drosophila species [28].

In the present study, a fragment of $\sim 400$ bp of the $A n$. cruzii timeless gene was used as a molecular marker to assess intraspecific variability and genetic divergence among six populations of An. cruzii captured in different locations within the geographic distribution range of this species in Brazil.

\section{Methods \\ Mosquitoes}

All mosquitoes used in this study were females captured at the following localities along the Brazilian Atlantic forest: Florianópolis, Santa Catarina State (SC) $\left(27^{\circ} 31^{\prime} \mathrm{S} /\right.$ $48^{\circ} 30^{\prime} \mathrm{W}$ ), Cananéia and Juquitiba, São Paulo State (SP) $\left(25^{\circ} 01^{\prime} \mathrm{S} / 47^{\circ} 55^{\prime} \mathrm{W}\right.$ and $\left.23^{\circ} 57^{\prime} \mathrm{S} / 47^{\circ} 03^{\prime} \mathrm{W}\right)$, Itatiaia, Rio de Janeiro State (RJ) $\left(22^{\circ} 27^{\prime} \mathrm{S} / 44^{\circ} 36^{\prime} \mathrm{W}\right)$, Santa Teresa, Espírito Santo State (ES) $\left(19^{\circ} 56^{\prime} \mathrm{S} / 40^{\circ} 35^{\prime} \mathrm{W}\right)$ and Itaparica Island (Jaguaripe), Bahia State (BA) $\left(13^{\circ} 05^{\prime} \mathrm{S} /\right.$ $38^{\circ} 48^{\prime} \mathrm{W}$ ) (Figure 1). All mosquitoes were primarily identified on the basis of their morphology according to Con- 


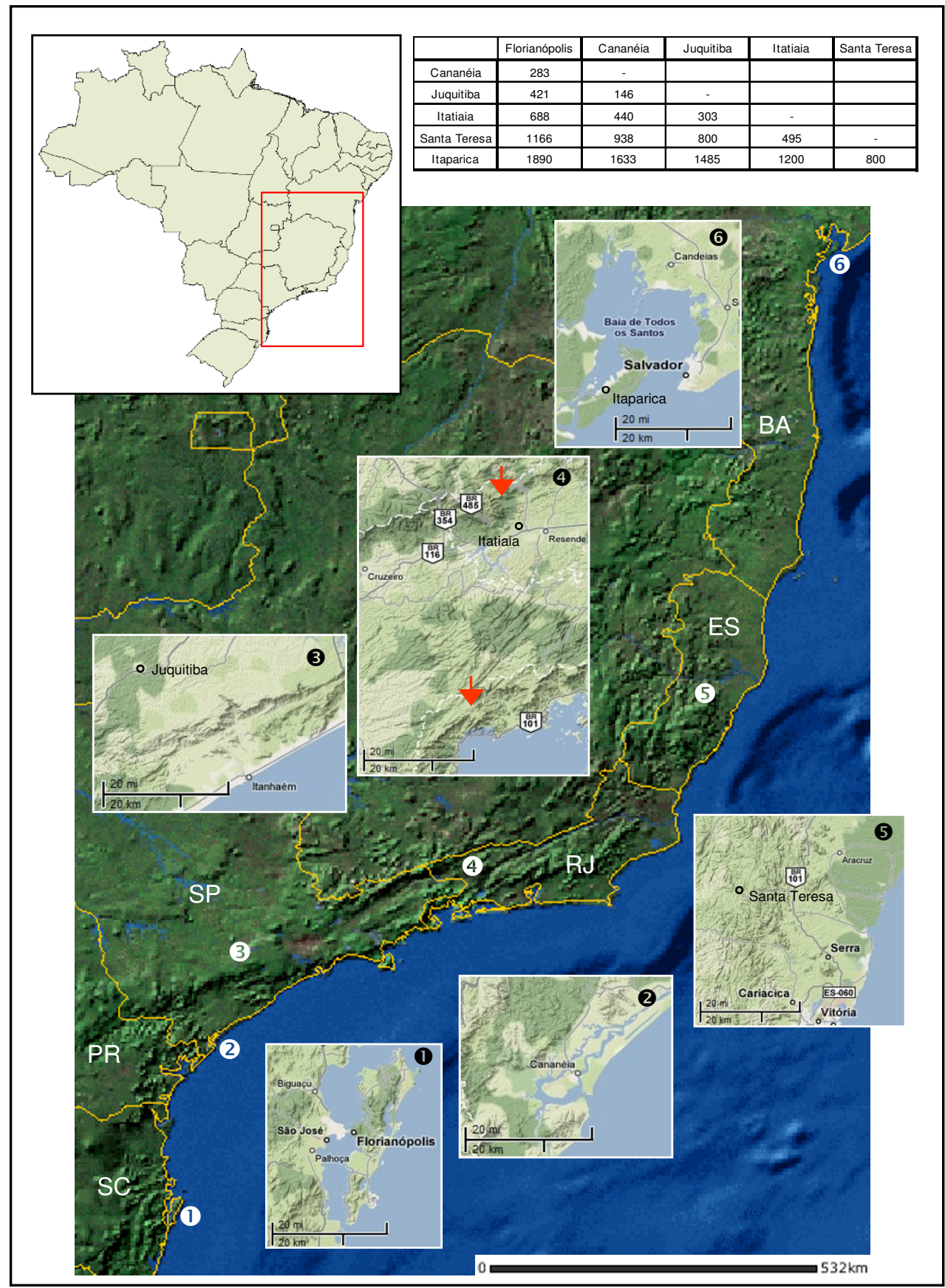

Figure I

Anopheles cruzii populations. Localities where the six Brazilian An. cruzii populations were collected. Values in table are approximated distances between localities in $\mathrm{km}$. The red arrows on box 4 show the two mountain chains around Itatiaia. The upper arrow shows the Serra da Mantiqueira and the lower shows Serra do Mar mountain chains (Source: IBGE and Google Maps). 
soli and Lourenço-de-Oliveira [5]. A total of 67 individuals (12 from Florianópolis, 12 from Cananéia, 11 from Juquitiba, 12 from Itatiaia, 6 from Santa Teresa and 14 from Itaparica, Bahia) were used for molecular assays.

\section{Isolation of the An. cruzii timeless gene sequence}

To design specific primers for the An. cruzii timeless gene sequence, genomic DNA was extracted from 10 females according to Jowett [32]. Initially, a pair of degenerated primers based on conserved regions of the TIMELESS proteins from Drosophila melanogaster and Anopheles gambiae named here 5'timdeg03 and 3'timdeg03 was used (Table 1; see also Figure 2) [33]. PCR was carried out with an Eppendorf Mastercycler ${ }^{\circledR}$ thermocycler using the following conditions: 15 cycles at $94^{\circ} \mathrm{C}$ for $60 \mathrm{~s}, 50^{\circ} \mathrm{C}$ (decreasing $1{ }^{\circ} \mathrm{C} /$ cycle) for $90 \mathrm{~s}$ and $72^{\circ} \mathrm{C}$ for $60 \mathrm{~s}$, following 20 cycles of $94^{\circ} \mathrm{C}$ for $60 \mathrm{~s}, 50^{\circ} \mathrm{C}$ for $90 \mathrm{~s}$ and $72^{\circ} \mathrm{C}$ for $60 \mathrm{~s}$. The products obtained were then purified and cloned in either Zero Blunt TOPO PCR cloning kit (Invitrogen) or pMOS Blue vector blunt-ended cloning kit (Amersham Biosciences). Sequencing of positive clones was carried out in an ABI Prism 377 or ABI Prism 3730 DNA sequencer at the Oswaldo Cruz Institute using the ABI Prism Big Dye Terminator Cycle Sequencing Ready Reaction kit (Applied Biosystems). The identity of the cloned fragments was determined by BlastX analysis using the GenBank [34]. To enlarge the timeless gene fragment in An. cruzii, a specific forward primer ( 5 'darltim02a) based on a fragment of the Anopheles darlingi timeless gene (Gentile \& Peixoto, unpublished) was used in combination with the specific reverse primer previously designed for An. cruzii (3'cruziitim03) in a PCR that amplified a fragment of $450 \mathrm{bp}$. This 450 bp fragment from the An. cruzii genome was then purified, cloned and sequenced as above. After checking the sequence identity, two new specific forward primers named 5'cruziitim02 and 5'acbatim02a (Table 1 and Figure 2) were designed and in combination with the reverse primer 3'cruziitim03 allowed the amplification of a 400 bp fragment of the An. cruzii timeless gene.

Interpopulational analysis of the An. cruzii timeless gene Females were processed individually and genomic DNA was extracted as above [32]. PCR amplification was car-

Table I: Sequence of primers used to amplify the timeless gene fragments

\begin{tabular}{ll}
\hline Primers Name & Sequence of primers at 5' $\rightarrow$ 3' \\
\hline 5'timdeg03 & AARGARTTYACNGTNGAYTT (forward) \\
3'timdeg03 & GTNACNARCCARAARAARTG (reverse) \\
3'cruziitim03 & GACGTATCGATCTGCACTT (reverse) \\
5'cruziitim02 & CGCTTCAATGCCGCAAATA (forward) \\
5'acbatim02a & GCCGCAAATAAGCACCG (forward)
\end{tabular}

Degenerate and specific primers used to amplify the timeless gene fragments in all Anopheles cruzii populations. ried out for 35 cycles at $94^{\circ} \mathrm{C}$ for $30 \mathrm{~s}, 62^{\circ} \mathrm{C}$ for $60 \mathrm{~s}$ and $72^{\circ} \mathrm{C}$ for $90 \mathrm{~s}$ using the proofreading $\mathrm{Pfu}$ DNA polymerase (Biotools) and primers $5^{\prime}$ acbatim02a or 5 'cruziitim02 and 3 'cruziitim03 (Table 1). Negative controls (no DNA added) were included in all amplification reactions and pre- and post-PCR procedures did not share equipment or reagents. After cloning the fragments obtained as above, at least eight clones of each mosquito were sequenced and two consensus sequences representing both alleles were generated. When only one haplotype was observed among the eight sequences the mosquito was considered a homozygote. The probability that a heterozygote will be mistakenly classified as a homozygote with this procedure is less than $1 \%$. Five mosquitoes were classified as homozygotes in Itatiaia, none in Florianópolis and one in each of the other four populations. The sequences obtained in homozygote mosquitoes were duplicated prior to analysis. However, the population genetics analysis was also carried out without duplicating the homozygote sequences and the results were very similar.

\section{DNA sequence analysis}

The timeless gene fragments were aligned using the GCG package (Wisconsin Package Version 10.2, Genetics Computer Group) and ClustalX software [35]. Analyses of the polymorphism and differentiation between populations were performed using DNASP4.0 [36] and $\mathrm{P}_{\mathrm{RO}} \mathrm{S}_{\mathrm{EQ}}$ programs [37]. $F_{S T}$ was calculated as described by Hudson et al [38] and significance was evaluated by 1,000 random permutations. Phylogenetic analysis was carried out using MEGA 4.0 [39] using the default parameters.

\section{Results}

Isolation of An. cruzii timeless gene fragment

Different PCR schemes were tested to amplify a fragment of the An. cruzii timeless gene (see Methods). Figure 2 shows an alignment of the predicted amino acid sequence encoded by this fragment obtained from An. cruzii compared to the TIMELESS protein of other insect species $(D$. melanogaster, Aedes aegypti and An. gambiae). A fairly high degree of inter-specific similarity is observed, but the putative protein encoded by 5 ' end of this fragment is variable, presenting some amino acid changes among the species compared. Figure 2 also shows the approximate positions of the two introns that occur in this region of the gene, as well as the location of the primers used to amplify the fragment from An. cruzii used for the population genetics analysis described below.

\section{Molecular variation and divergence among An. cruzii populations}

The geographic distribution of the six Brazilian populations of An. cruzii used in this study is shown at Figure 1. Initially, using the primers 5'cruziitim02 and 3 'cruziitim03 (see Figure 2), a 420 bp fragment of the 
D. melanogaster

Ae. aegypti

An. gambiae

An. cruzii

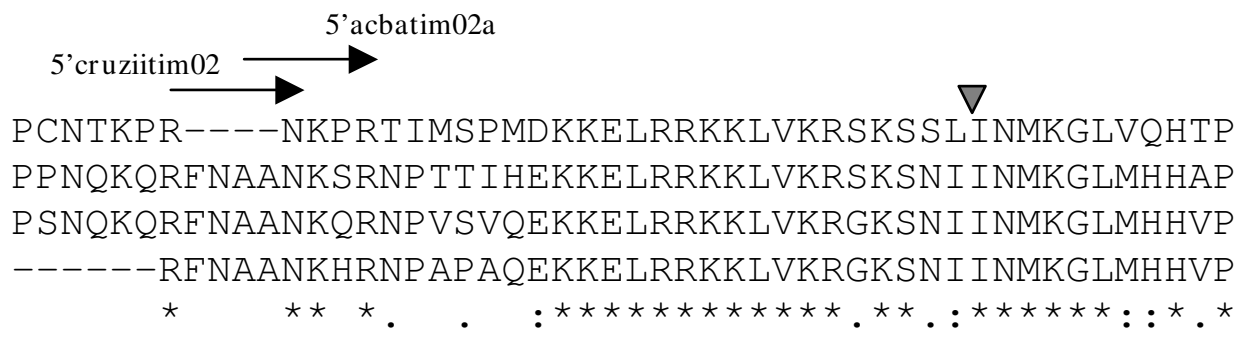

5'timdeg03

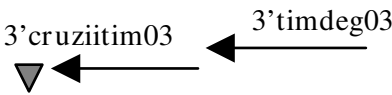

TDDD I SNLLKEFTVDF LLKGYSYLVEELHMQLLSNAKVP IDTSHFFWLVT SDDD I SHILKEFTVDF LLKGYGF LVQELHAQLLSDLQVQIDT SHFFWLVT TDDD I SHILKEFTVDF LLKGYGYLVHELHTQLLSDLQVQIDTSHFFWLVT TDDD ISHILKEFTVDF LLKGYGYLVQELHSQLLSDLQVQIDTS-------

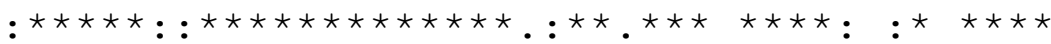

\section{Figure 2}

Timeless protein multiple alignment and primer positions. The putative fragment of An. cruzii TIMELESS deduced protein is aligned with D. melanogaster, An. gambiae and Ae. aegypt homologues. Arrows point to the approximated positions of the primers used in this study. The inverted triangles represent the positions of the two introns.

timeless gene was amplified in all An. cruzii populations analyzed, with the exception of samples from Bahia State (Itaparica Island), which revealed a 400 bp amplification product, indicating the existence of length variation among the studied populations. The sample from Bahia, however, displayed lower amplification in some cases using these primers, and so a new internal forward primer named 5'acbatim02a (Table 1) was designed based on the initial sequences obtained. Using this new primer in conjunction with 3 'cruziitim03, a $\sim 410$ bp fragment of time- less gene was obtained for all An. cruzii populations from south and south-east Brazil and a 390 bp from Bahia.

A total of 24 sequences from Florianópolis, 24 from Cananéia, 22 from Juquitiba, 24 from Itatiaia, 12 from Santa Teresa and 28 from Itaparica (Bahia State) populations were obtained. The sequences were submitted to GenBank (accession numbers: FJ408732 - FJ408865). A full alignment of all sequences is shown in Additional file 1. Most of the base substitutions were silent or occurred

Table 2: Polymorphisms of all An. cruzii populations

\begin{tabular}{|c|c|c|c|c|c|c|c|}
\hline Population & $n$ & $\mathrm{~S}$ & $\theta$ & $\pi$ & $D_{\mathrm{T}}$ & $D_{\mathrm{FL}}$ & $F_{\mathrm{FL}}$ \\
\hline Florianópolis & 24 & $\begin{array}{c}57 \\
(17)\end{array}$ & $\begin{array}{c}0.04258 \\
(0.02322)\end{array}$ & $\begin{array}{c}0.03018 \\
(0.01483)\end{array}$ & $\begin{array}{c}-1.00660 \\
(-1.24295)\end{array}$ & $\begin{array}{c}-0.62541 \\
(-1.24456)\end{array}$ & $\begin{array}{c}-0.87450 \\
(-1.45349)\end{array}$ \\
\hline Cananéia & 24 & $\begin{array}{c}46 \\
(12)\end{array}$ & $\begin{array}{c}0.03334 \\
(0.01665)\end{array}$ & $\begin{array}{c}0.02677 \\
(0.01021)\end{array}$ & $\begin{array}{c}-0.64691 \\
(-1.30282)\end{array}$ & $\begin{array}{c}-0.47115 \\
(-0.96989)\end{array}$ & $\begin{array}{c}-0.61709 \\
(-1.24756)\end{array}$ \\
\hline Juquitiba & 22 & $\begin{array}{c}52 \\
(20)\end{array}$ & $\begin{array}{c}0.03522 \\
(0.02652)\end{array}$ & $\begin{array}{c}0.03086 \\
(0.02217)\end{array}$ & $\begin{array}{c}-0.48955 \\
(-0.51723)\end{array}$ & $\begin{array}{c}-0.47485 \\
(-0.34701)\end{array}$ & $\begin{array}{c}-0.56076 \\
(-0.46415)\end{array}$ \\
\hline Itatiaia & 24 & $\begin{array}{c}26 \\
(12)\end{array}$ & $\begin{array}{c}0.01864 \\
(0.01665)\end{array}$ & $\begin{array}{c}0.01829 \\
(0.01825)\end{array}$ & $\begin{array}{l}-0.00645 \\
(0.40503)\end{array}$ & $\begin{array}{l}-0.32168 \\
(0.25917)\end{array}$ & $\begin{array}{c}-0.25815 \\
(0.35329)\end{array}$ \\
\hline Santa Teresa & 12 & $\begin{array}{c}35 \\
(15)\end{array}$ & $\begin{array}{c}0.03042 \\
(0.02558)\end{array}$ & $\begin{array}{c}0.02518 \\
(0.02248)\end{array}$ & $\begin{array}{c}-0.65598 \\
(-0.41589)\end{array}$ & $\begin{array}{c}-0.86793 \\
(-0.58337)\end{array}$ & $\begin{array}{c}-0.92570 \\
(-0.61405)\end{array}$ \\
\hline Bahia & 28 & $\begin{array}{l}24 \\
(9)\end{array}$ & $\begin{array}{c}0.01661 \\
(0.01099)\end{array}$ & $\begin{array}{c}0.01035 \\
(0.00571)\end{array}$ & $\begin{array}{c}-1.31797 \\
(-1.49603)\end{array}$ & $\begin{array}{c}-0.83982 \\
(-0.91433)\end{array}$ & $\begin{array}{c}-1.16519 \\
(-1.27249)\end{array}$ \\
\hline
\end{tabular}

$n$, number of DNA sequences of each population; $\mathrm{S}$, number of polymorphic (segregating) sites; $\theta$, nucleotide diversity based on the total number of mutations (Eta); $\pi$, nucleotide diversity based on the average number of pair-wise differences; $D_{\mathrm{T}}$, Tajima's [40]D; $D_{\mathrm{FL}}$, Fu \& Li's [4I]D and $F_{\mathrm{FL}}$, Fu \& Li's [4I]F, based on the total number of mutations. In no cases were Tajima's $D$-values or Fu \& Li's $D$ and $F$-values significant $(P>0.10$ in all cases). The values in parentheses were calculated using only coding regions of the timeless gene fragment. 
within the two introns, which show a number of indels. A few non-synonymous changes were also observed, causing seven amino acid differences among the sequences.

Table 2 shows the number of DNA sequences of each $A n$. cruzii population studied $(n)$ and the number of polymorphic sites (S). The values in parentheses were calculated using only coding regions of the timeless gene fragment. Based on the sequences, two measures of nucleotide diversity were calculated for each population: $\pi$, based on the average number of pair-wise differences and $\theta$, based on the total number of mutations (Table 2). The population from Bahia was the least polymorphic, showing the lowest values of $\theta$ and $\pi$, as well as the smaller number of polymorphic sites (S). Table 2 also shows the results of Tajima [40] and $\mathrm{Fu} \mathrm{\&} \mathrm{Li}[41]$ tests of natural selection, based on the total number of mutations of each population. In all cases, Tajima's $D$ or Fu \& Li's $D$ and $F$ statistics were non-significant $(P>0.10)$ indicating no deviations from neutrality.

Table 3 shows the pair-wise estimates of population differentiation $\left(F_{S T}\right)$ between all An. cruzii populations. In all cases the $F_{S T}$ values were significant, except for the comparison between Juquitiba and Santa Teresa when the coding regions of the timeless gene fragment were used. Very high $F_{S T}$ values were found between Bahia State and the others $(0.8353-0.8761)$. The average number of nucleotide substitutions per site (Dxy) and the number of net nucleotide substitutions per site between populations $(D a)$ are shown in Table 3 . The distribution of the four mutually exclusive categories of segregating sites observed in each comparison, i.e. the number of polymorphisms exclusive for each population (S1 and $S 2)$, the number of shared polymorphisms $(S s)$ and the number of fixed differences $(S f)$ between populations are also included in Table 3. These polymorphic and fixed sites include some of the non-synonymous changes observed (see Table 4 for a detailed description).

The values using only coding regions (shown in parentheses in Table 3) show some differences compared with those obtained with the whole sequence. Yet even using the more conserved coding regions, the values of differentiation between the population from Bahia and all others revealed a high number of fixed differences and only a few shared polymorphisms. Among the southern and southeastern populations, there were shared polymorphisms and no fixed differences, suggesting they belong to the same or to very closely related species.

\section{Divergence time between An. cruzii populations}

The estimate of the time of divergence between An. cruzii populations from Bahia and the others were calculated using the $D a$ value based on the third codon positions. This estimate assumed that substitutions rates observed between An. cruzii from Bahia State and the other populations originally from southern regions of Brazil are similar to the estimated rates in the same fragment of the timeless gene between closely related Drosophila persimilis and Drosophila pseudoobscura, species that diverged around 0.85 millions of years ago (MYA) (FlyBase Accession Numbers

Table 3: Genetic differentiation between all An. cruzii populations

\begin{tabular}{|c|c|c|c|c|c|c|c|c|}
\hline Populations & $F_{S T}$ & $P$-value & Dxy & $D a$ & $S_{s}$ & $S_{f}$ & $S_{1}$ & $S_{2}$ \\
\hline I. Florianópolis $\times$ Cananéia & $0.0548(0.0622)$ & $0.002(0.003)$ & $0.0308(0.0136)$ & $0.0017(0.0008)$ & $30(7)$ & $0(0)$ & $28(\mathrm{II})$ & $17(6)$ \\
\hline 2. Juquitiba $\times$ Santa Teresa & $0.0693(0.0487)$ & $0.040(0.156)$ & $0.0290(0.0236)$ & $0.0020(0.0011)$ & $21(10)$ & $0(0)$ & $26(10)$ & II (6) \\
\hline 3. Florianópolis $\times$ Juquitiba & $0.0875(0.1384)$ & $0.000(0.000)$ & $0.0333(0.0216)$ & $0.0029(0.0030)$ & $21(8)$ & $0(0)$ & $37(10)$ & $26(12)$ \\
\hline 4. Cananéia $\times$ Juquitiba & $0.1077(0.1849)$ & $0.002(0.000)$ & $0.0322(0.0201)$ & $0.0035(0.0037)$ & $20(5)$ & $0(0)$ & $27(8)$ & $27(15)$ \\
\hline 5. Florianópolis $\times$ Itatiaia & $0.1450(0.2078)$ & $0.000(0.000)$ & $0.0293(0.0213)$ & $0.0042(0.0044)$ & $16(7)$ & $0(0)$ & $42(I I)$ & II (6) \\
\hline 6. Florianópolis $\times$ Santa Teresa & $0.1582(0.2652)$ & $0.000(0.000)$ & $0.0325(0.0256)$ & $0.005 I(0.0068)$ & $14(8)$ & $0(0)$ & $44(10)$ & $18(8)$ \\
\hline 7. Itatiaia $\times$ Santa Teresa & $0.1837(0.2414)$ & $0.000(0.000)$ & $0.0265(0.0273)$ & $0.0049(0.0066)$ & $10(6)$ & $0(0)$ & $17(7)$ & $22(10)$ \\
\hline 8. Juquitiba $\times$ Itatiaia & $0.2030(0.2078)$ & $0.000(0.000)$ & $0.0310(0.0258)$ & $0.0063(0.0054)$ & $10(6)$ & $0(0)$ & $37(14)$ & $17(7)$ \\
\hline 9. Cananéia $\times$ Santa Teresa & $0.2154(0.3152)$ & $0.000(0.000)$ & $0.0328(0.0243)$ & $0.007 \mid(0.0076)$ & II (4) & $0(0)$ & $36(9)$ & $21(12)$ \\
\hline 10. Cananéia $\times$ Itatiaia & $0.225 \mathrm{I}(0.2720)$ & $0.000(0.000)$ & $0.0302(0.0201)$ & $0.0068(0.0055)$ & $8(3)$ & $0(0)$ & $39(10)$ & $19(10)$ \\
\hline II. Florianópolis $\times$ Bahia & $0.8353(0.8345)$ & $0.000(0.000)$ & $0.1197(0.0625)$ & $0.1000(0.0522)$ & $6(4)$ & $27(7)$ & $52(14)$ & $17(5)$ \\
\hline 12. Juquitiba $\times$ Bahia & $0.8403(0.7874)$ & $0.000(0.000)$ & $0.1212(0.0656)$ & $0.1019(0.0516)$ & $2(1)$ & $30(8)$ & $45(19)$ & $21(8)$ \\
\hline 13. Cananéia $\times$ Bahia & $0.8506(0.8703)$ & $0.000(0.000)$ & $0.1211(0.0626)$ & $0.1030(0.0545)$ & $I(0)$ & $29(8)$ & $46(13)$ & $22(9)$ \\
\hline 14. Santa Teresa $\times$ Bahia & $0.8624(0.7926)$ & $0.000(0.000)$ & $0.1187(0.0685)$ & $0.1024(0.0543)$ & $3(2)$ & $32(9)$ & $29(14)$ & $20(7)$ \\
\hline I5. Itatiaia $\times$ Bahia & $0.876 \mathrm{I}(0.8020)$ & $0.000(0.000)$ & $0.1130(0.0617)$ & $0.0990(0.0495)$ & $3(2)$ & $30(8)$ & $24(\mathrm{II})$ & $20(7)$ \\
\hline 16. *An. cruzii $\times$ Bahia & $0.8370(0.7935)$ & $0.000(0.000)$ & $0.1187(0.037)$ & $0.0993(0.0505)$ & $8(5)$ & $25(6)$ & 107 (39) & $15(4)$ \\
\hline
\end{tabular}

$F_{S T}$, pair-wise estimates of population differentiation. $P$-value, significance of $F_{S T}$ values (evaluated by 1,000 random permutations). $D x y$, average number of nucleotide substitutions per site between populations [49]; $\mathrm{Da}$, number of net nucleotide substitutions per site between populations [49]. SI, number of polymorphic sites exclusive to the first population shown in the first column. S2, number of polymorphic sites exclusive to the second population shown in the first column. Ss, number of shared polymorphisms between the two populations. Sf, number of fixed differences between the two populations. The values in parentheses were calculated using only coding regions of the timeless gene fragment. *An. cruzii: all populations from south and south-east Brazil together without Bahia population. 
Table 4: Non-synonymous changes on the timeless gene fragment

\begin{tabular}{|c|c|c|c|}
\hline \multicolumn{4}{|l|}{ Polymorphic Sites: } \\
\hline Site Position: & Individuals: & Codon: & Amino acid: \\
\hline \multirow[t]{2}{*}{05 (first codon base) } & Individuals from all populations analysed & $\mathrm{CCC}$ & Proline \\
\hline & Can03a & TCC & Serine \\
\hline \multirow[t]{2}{*}{06 (second codon base) } & Individuals from all populations analysed & $\mathrm{CCC}$ & Proline \\
\hline & Juq66a; Juq66b; Can06b; Can I2b & CTC & Leucine \\
\hline \multirow[t]{2}{*}{08 (first codon base) } & Individuals from south and south-east populations & GCG & Alanine \\
\hline & All individuals from Bahia population and Flo37a; Can02b & ACG & Threonine \\
\hline \multirow[t]{2}{*}{ I8 (second codon base) } & All individuals from south and south-east populations and Bahia I9a; Bahia33a; Bahia20b & CAG & Glutamine \\
\hline & Individuals from Bahia population & CTG & Leucine \\
\hline \multicolumn{4}{|l|}{ Fixed Differences: } \\
\hline Site Position: & Individuals: & Codon: & Amino acid: \\
\hline \multirow[t]{2}{*}{ II (first codon base) } & All individuals from Florianópolis, Cananéia, Juquitiba, Itatiaia and Santa Teresa populations & CCG & Proline \\
\hline & All individuals from Bahia population & TCG & Serine \\
\hline \multirow[t]{2}{*}{188 (first codon base) } & All individuals from Florianópolis, Cananéia, Juquitiba, Itatiaia and Santa Teresa populations & ACG & Threonine \\
\hline & All individuals from Bahia population & TCG & Serine \\
\hline \multirow[t]{2}{*}{275 (first codon base) } & All individuals from Florianópolis, Cananéia, Juquitiba, Itatiaia and Santa Teresa populations & TCC & Serine \\
\hline & All individuals from Bahia population & $\mathrm{ACC}$ & Threonine \\
\hline
\end{tabular}

List of non-synonymous changes on the studied timeless gene fragment between An. cruzii populations. Flo: Florianópolis population; Can: Cananéia population; Juq: Juquitiba population; Ita: Itatiaia population; San: Santa Teresa population; Bahia: Bahia population.

FBtr0185090 and FBtr0282161, respectively) [42]. The divergence observed for the timeless gene between these two Drosophila species based on the third codon positions is 0.03030 . Based on the $D a$ value $(0.05426)$, the estimated time of divergence between An. cruzii populations from south and south-east Brazil and that from Bahia State, is approximately 1.5 MYA.

\section{Genealogy of the An. cruzii timeless sequences}

Figure 3 shows a Neighbour-joining tree of the sequences from all An. cruzii populations using the Kimura 2-parameter distance and the timeless gene sequences. The resulting tree showed no clear separation between the sequences of the populations from Florianópolis, Cananéia, Juquitiba, Itatiaia and Santa Teresa, but some differentiation was evident since the sequences do not appear at random in the tree, especially in the case of Itatiaia. The An. cruzii sequences from the Bahia population, however, were clearly separated on an isolated branch.

\section{Discussion}

Zavortink [4] pointed out morphological differences in the larval stage of populations of An. cruzii from Rio de Janeiro and Santa Catarina States, suggesting that $A n$. cruzii could represent more than a single species. A moderately high $F_{S T}$ value between Florianópolis (Santa Catarina State) and Itatiaia (Rio de Janeiro State) populations was reported here. In addition, comparison of Itatiaia with the other populations (excluding Bahia) revealed even higher $F_{S T}$ values, perhaps suggesting that this population is indeed in a process of differentiation and incipient speciation. Moreover, sequences from Itatiaia showed some clustering in the Neighbour-joining tree (Figure 3). Itatiaia was also the least polymorphic population of south and south-east Brazil and showed the highest number of homozygotes suggesting some inbreeding. It is possible that this reflects a smaller effective size and the relative isolation of this population, since its location in a valley between two mountain chains (Serra do Mar and Serra da Mantiqueira - Figure 1) might reduce gene flow with other populations.

In a recent review, Ayala and Coluzzi [43] argue that many siblings are outcomes of recent speciation processes associated with paracentric inversions, mostly involving the $X$ chromosome. Ramirez and Dessen $[23,24]$, studying the $X$ chromosome banding patterns and inversion frequencies of distinct populations of An. cruzii from south and south-east Brazil, showed that there are three $X$ chromosomal forms (A, B and C), suggesting a process of incipient speciation acting on An. cruzii populations. Among the localities analysed in this study, only Juquitiba and Cananéia were also investigated by Ramirez and Dessen $[23,24]$. They observed that in Juquitiba the majority of mosquitoes had form A and the remainder had form C, while in Cananéia form $B$ predominated with the remainder having form A $[23,24]$. Although the differentiation in the timeless gene between these two populations is not 


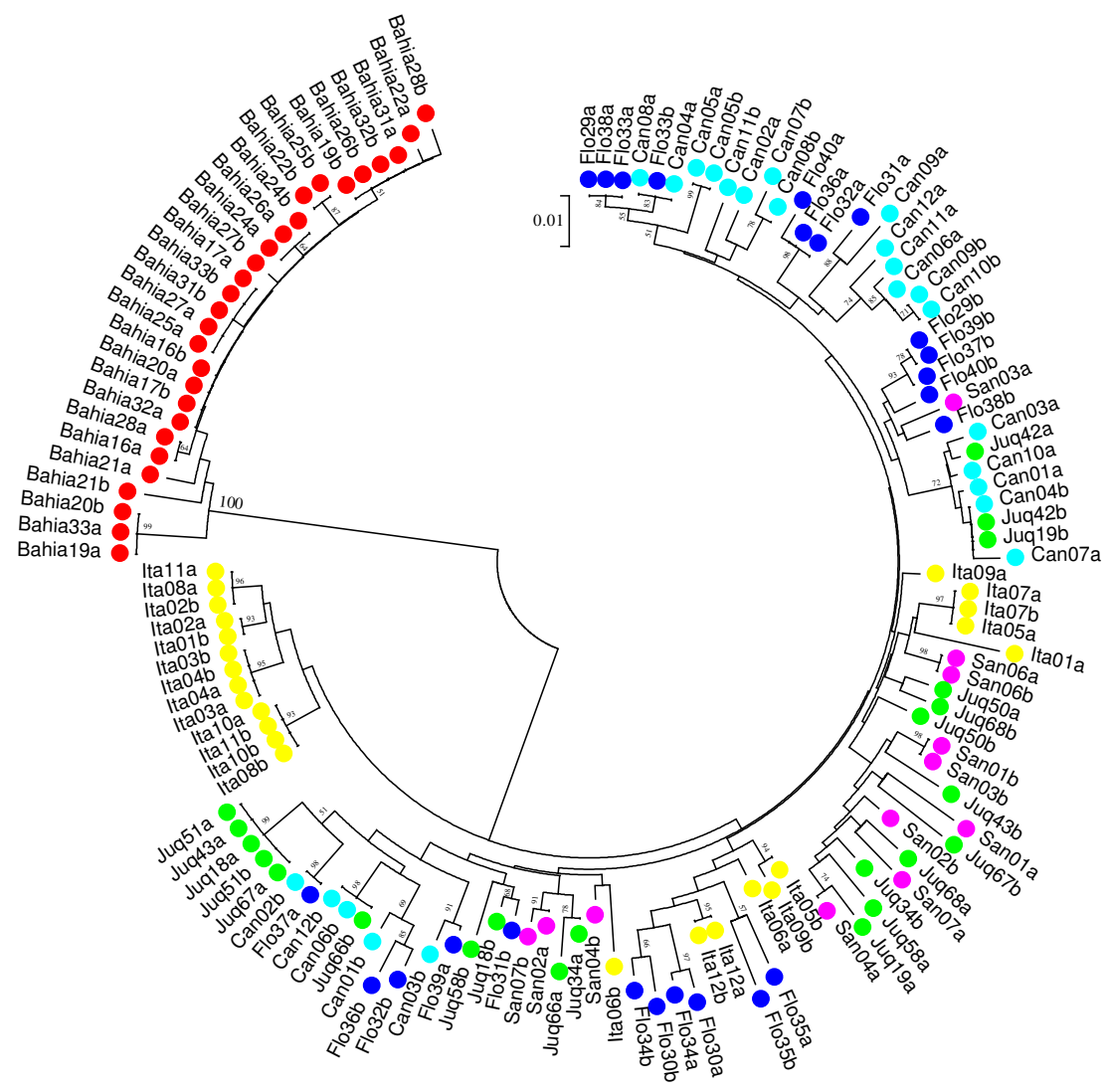

Figure 3

Neighbour-joining tree. Neighbour-joining tree using timeless nucleotide sequences of the Anopheles cruzii populations obtained with Kimura 2-parameters distance. Numbers on the nodes represent the percentage bootstrap values based on I,000 replications. Flo: Florianópolis population; Can: Cananéia; Juq: Juquitiba; Ita: Itatiaia; San: Santa Teresa; Bahia: Itaparica Island population.

high, the $F_{S T}$ value is significant and does not contradict the results of the chromosomal analysis. The relatively low differentiation in timeless among most populations from south and south-east Brazil might reflect introgression at this locus. It would be interesting to analyse the same populations with an $X$-linked molecular marker to see whether a higher level of differentiation is found.

Recently, Malafronte et al [26] compared sequences of ITS2 (Internal Spacer Region 2) from several An. cruzii populations from south and south-east Brazil. Although, they found some differences between sequences from different localities, including Juquitiba and Cananéia, they considered premature to conclude based on their results that there are distinct sibling species in the areas they investigated. Similar results were observed by Calado et al [44] using PCR-RAPD and PCR-RFLP of the ITS2 region.
Very strong evidence was presented here that confirms the existence of a different species in Bahia State, a finding that supports a previous isoenzyme study [25]. The extremely high $F_{S T}$ values detected between this population and the other five populations studied, as well as the higher number of fixed differences observed, show that Bahia represents a different species. This population also presented lower levels of variability than those from south and south-east Brazil, possibly indicating a smaller population size or past founder effects. However, although the isoenzyme heterozygosity reported for Bahia is lower than Cananéia it is similar to that observed in Florianópolis [25].

A very rough estimate suggests that the divergence between the Bahia population and the more southern populations of An. cruzii possibly occurred around 1.5 
MYA, during the Pleistocene. Climate changes during this period such as an intense precipitation decrease and more arid conditions fragmented the Brazilian Atlantic forest [45] creating refugia that played an important role in the differentiation among populations of a number of forest species, such as marmosets [46], tree frogs and many others [47]. Forest fragmentation has also been proposed to explain differentiation among populations of the Atlantic forest mosquito Sabethes albiprivus [48]. Since An. cruzii is also a forest-obligate species, it is possible that the Bahia and southern populations of this species complex suffered fragmentation due a constriction of the forest. Although Tajima's $D$ and Fu \& Li's $D$ and $F$ statistics were non-significant, they were negative in most cases and that is consistent with population expansion following the forest recovery after the Pleistocene. Analysis of a number of other molecular markers will allow more precise estimates of the divergence time between the Bahia population and those of south and south-east Brazil. It may also help in determining whether further An. cruzii siblings exist in the latter area.

Finally, although malaria cases are reported annually in Bahia State, the main vector implicated in Plasmodium spp. transmission in this area is An. darlingi and not An. cruzii, the most important vector in the southern states. This suggests that the differentiation observed within the An. cruzii complex might also explain aspects of the vectorial capacity of these mosquitoes, however further studies are needed to confirm or reject this hypothesis.

\section{Conclusion}

Analysis of the molecular polymorphism and genetic differentiation of the timeless gene among Brazilian populations of An. cruzii indicates that this malaria vector is a complex of at least two cryptic species, one occurring in the north-east (Bahia State) and another in south and south-east Brazil. In addition, the data also suggest that populations of the latter region might also constitute different incipient species and that further work might support the occurrence of other siblings within this complex in Brazil.

\section{Competing interests}

The authors declare that they have no competing interests.

\section{Authors' contributions}

LDPR participated in data generation and analysis, and drafted the manuscript. She also helped capture mosquitoes in Florianópolis. CJCP carried out the capture and morphological identification of mosquitoes collected in Florianópolis and Itaparica. CG participated in the cloning of An. cruzii timeless gene fragments. ECG participated in the DNA sequencing and helped to write the manuscript. AAP is the principal investigator, participated in its design and coordination, and helped to write the manuscript. All authors read and approved the final manuscript.

\section{Additional material}

\section{Additional file 1}

Alignment of the DNA sequences of An. cruzii. Alignment of the DNA sequences from the timeless gene fragment from all populations of An. cruzii analysed. The translated amino acid sequence is shown above the alignment and the introns are presented in the darkened regions. Dots represent the identity of the first nucleotide sequence and asterisks represent the identity of all sequences. The non-synonymous changes found among the sequences are highlighted in yellow boxes. Flo: individuals from Florianópolis; Can: Cananéia; Juq: Juquitiba; Ita: Itatiaia; San: Santa Teresa; Bahia: individuals from Itaparica Island, Bahia State. Click here for file

[http://www.biomedcentral.com/content/supplementary/14752875-8-60-S1.doc]

\section{Acknowledgements}

The authors are indebted to Dr Rosely dos Santos Malafronte (Instituto de Medicina Tropical de São Paulo), Dr Monique de Albuquerque Motta (FIOCRUZ - Rio de Janeiro) and Claudiney Biral dos Santos (Unidade de Medicina Tropical - Universidade Federal do Espirito Santo) for providing mosquitoes from Cananéia, Juquitiba, Itatiaia and Santa Teresa; to Paulo Amoretty and Robson Costa da Silva for their technical assistance, to $\mathrm{Dr}$ André Nóbrega Pitaluga for preparing Figure I, to Dr Julian Gray for reading the manuscript, and to PDTIS-FIOCRUZ for use of its DNA sequencing facility. This work was supported by grants from the Howard Hughes Medical Institute, FIOCRUZ, Faperj and CNPq.

\section{References}

I. Pittendrigh CS: The ectopic specialization of Anopheles homunculus, and its relation to competition with An. bellator. Evolution 1949, 4:64-78.

2. Veloso HP, De Moura JV, Klein RM: Ecological limitation of Anopheles of the Subgenus Kerteszia in the coastal region of Southern Brazil. Mem Inst Oswaldo Cruz 1956, 54:5 I7-548.

3. Rachou RG: Anofelinos do Brasil: Comportamento dasespécies vetoras de malária. Rev Bras Malariol Doencas Trop 1958 $10:|45-| 8 \mid$

4. Zavortink TJ: A review of the subgenus Kerteszia of Anopheles. Cont Am Entomol Inst 1973, 9: I-54.

5. Consoli RAGB, Lourenço-de-Oliveira R: Principais mosquitos de importância sanitária no Brasil Rio de Janeiro: Ed. Fiocruz; 1994.

6. Corrêa RR, Forattini OP, Guarita OF, Rabello EX: Observations on the flight of Anopheles (Kerteszia) cruzii and of $A$. (K.) bellator, vectors of malaria (Diptera, Culicidae). Arq Hig Saude Publica 1961, 26:333-342.

7. Aragão MB: Geographic distribution and abundance of Anopheles species (Kerteszia) (Diptera, Culicidae). Rev Bras Malariol Doencas Trop 1964, 16:73-109.

8. Wilkerson RC, Peyton EL: The Brazilian malaria vector Anopheles (Kerteszia) cruzii: Life stages and biology (Diptera: Culicidae). Mosq Syst 1991, 23: I 10-122.

9. Forattini OP, Kakitani I, Massad E, Gomes Ade C: Studies on mosquitoes (Diptera: Culicidae) and anthropic environment. I Parity of blood seeking Anopheles (Kerteszia) in south-eastern Brazil. Rev Saude Publica 1993, 27:I-8.

10. Bona AC, Navarro-Silva MA: Anopheles cruzii parity in dense rain forest in Southern Brazil. Rev Saude Publica 2006, 40: I I I8-I I 23. 
II. MS - Ministério da Saúde, Brazil (Brazilian Ministry of Health) 2006 [http://portal.saude.gov.br/portal/arquivos/pdf/ folder malaria 2006 web.pdf].

12. Machado RL, D' Almeida Couto AA, Cavasini CE, Calvosa VS Malaria outside the Brazilian Amazonian region: the situation in Santa Catarina State. Rev Soc Bras Med Trop 2003, 36:58I-586.

13. SESAB - Secretaria da Saúde do Estado da Bahia (Bahia State Health Department) [http://www.saude.ba.gov.br]

14. Davis NC, Kumm HHW: Further incrimination of Anopheles darlingi Root as a transmitter of malaria. Am J Trop Med 1932, I 2:93-95.

15. SINAN - Sistema de Informação de Agravos de Notificação, Ministério da Saúde [http://dtr2004.saude.gov.br/sinanweb/novol ]

16. Rezende HR, Cerutti C, Santos CB: Aspectos atuais da distribuição geográfica de Anopheles (Kerteszia) cruzii Dyar \& Knab, 1908 no Estado do Espírito Santo, Brasil. Entomol Vect 2005, I 2:123-126.

17. Deane LM, Ferreira-Neto JA, Deane SP, Silveira IP: Anopheles (Kerteszia) cruzii, a natural vector of the monkey malaria parasites, Plasmodium simium and Plamodium brasilianum. Trans $R$ Soc Trop Med Hyg 1970, 64:647.

18. Marrelli MT, Malafronte RS, Sallum MA, Natal D: Kerteszia subgenus of Anopheles associated with the Brazilian Atlantic rainforest: current knowledge and future challenges. Malar J 2007, 6:127-I34.

19. Deane LM, Ferreira-Neto JA, Lima MM: The vertical dispersion of Anopheles (Kerteszia) cruzii in a forest in southern Brazil suggests that human cases of simian origin be expect. Mem Inst Oswaldo Cruz 1984, 79:46I-463.

20. Ueno HM, Forattini OP, Kakitani I: Vertical and seasonal distribution of Anopheles (Kerteszia) in Ilha Comprida, Southeastern Brazil. Rev Saude Publica 2007, 41:269-275.

21. Ramirez CC, Dessen EM: Cytogenetics analysis of a natural population of Anopheles cruzii. Rev Bras Genet 1994, 17:41-46.

22. Ramirez CC, Dessen EM, Otto PA: Inversion polymorphism in a natural population of Anopheles cruzii. Caryologia 1994, 47: $121-130$.

23. Ramirez CC, Dessen EM: Chromosomal evidence for sibling species of the malaria vector Anopheles cruzii. Genome 2000, 43:|43-|5|.

24. Ramirez CC, Dessen EM: Chromosome differentiated populations of Anopheles cruzii: evidence for a third sibling species. Genetica 2000, 108:73-80.

25. Carvalho-Pinto CJ, Lourenço-de-Oliveira R: Isoenzymatic analysis of four Anopheles (Kerteszia) cruzii (Díptera: Culicidae) populations of Brazil. Mem Inst Oswaldo Cruz 2004, 99:47I-475.

26. Malafronte Rdos S, Marrelli MT, Ramirez CC, Nassar MN, Marinotti $O$ : Intraspecific variation of second internal transcribed spacer of nuclear ribosomal DNA among populations of Anopheles (Kerteszia) cruzii (Diptera: Culicidae). J Med Entomol 2007, 44:538-542

27. Hardin PE: The Circadian Timekeeping System of Drosophila. Curr Biol 2005, 15:7|4-722.

28. Sakai $\mathrm{T}$, Ishida $\mathrm{N}$ : Circadian rhythms of female mating activity governed by clock genes in Drosophila. Proc Natl Acad Sci 200I, 98:922I-9225

29. Tauber E, Roe H, Costa R, Hennessy JM, Kyriacou CP: Temporal mating isolation driven by a behavioral gene in Drosophila. Curr Biol 2003, 13:140-145.

30. Pittendrigh CS: The quantitative evaluation of Kerteszia breeding grounds. Am J Trop Med Hyg 1950, 30:457-468.

31. Chahad-Ehlers S, Lozovei AL, Marques MD: Reproductive and post-embryonic daily rhythm patterns of the malaria vector Anopheles (Kerteszia) cruzii: aspects of the life cycle. Chronobiol Int 2007, 24:289-304.

32. Jowett T: Preparation of nucleic acids. In Drosophila, A Practical Approach IRL press, Oxford: Roberts DB; 1998:347-37I.

33. Gentile C, Meireles-Filho AC, Britto C, Lima JB, Valle D, Peixoto AA: Cloning and daily expression of the timeless gene in Aedes aegypti (Diptera:Culicidae). Insect Biochem Mol Biol 2006, 36:878-884.

34. GenBank database [http://www.ncbi.nlm.nih.gov/BLAST/]

35. Thompson JD, Gibson T], Plewniak F, Jeanmougin F, Higgins DG: The CLUSTAL_X windows interface: flexible strategies for mul- tiple sequence alignment aided by quality analysis tools. Nucleic Acids Res 1997, 25:4876-4882.

36. Rozas J, Sánchez-DelBarrio JC, Messeguer X, Rozas R: DnaSP, DNA polymorphism analyses by the coalescent and other methods. Bioinformatics 2003, 19:2496-2497.

37. Filatov DA, Charlesworth D: DNA polimorphism, haplotype structure and balancing selection in the Leavenworthia PgiC locus. Genetics 1999, I 53:1423-1434.

38. Hudson RR, Slatkin M, Maddison WP: Estimation of levels of gene flow from DNA sequence data. Genetics 1992, 132:583-589.

39. Tamura K, Dudley J, Nei M, Kumar S: MEGA4: Molecular Evolutionary Genetics Analysis (MEGA) software version 4.0. Mol Biol Evol 2007, 24:1596-I599.

40. Tajima F: Statistical method for testing the neutral mutation hypothesis by DNA polymorphism. Genetics 1989, | 23:585-595.

4I. Fu YX, Li WH: Statistical tests of neutrality of mutations. Genetics 1993, 133:693-709.

42. Tamura K, Subramanian S, Kumar S: Temporal Patterns of Fruit Fly (Drosophila) Evolution Revealed by Mutation Clocks. Mol Biol Evol 2004, 2 I (I):36-44.

43. Ayala FJ, Coluzzi M: Chromosome speciation: Humans, Drosophila, and mosquitoes. Proc Natl Acad Sci 2005, 102:6535-6542.

44. Calado DC Navarro-Silva MA Sallum MAM: PCR-RAPD and PCR-RFLP polymorphism detected in Anopheles cruzii (Diptera, Culicidae). Rev Bras Entomol 2006, 50:423-430.

45. Vasconcelos PM, Becker TA, Renne PR, Brimhall GH: Age and duration of weathering by $40 \mathrm{~K}-40 \mathrm{Ar}$ and $40 \mathrm{Ar} / 39 \mathrm{Ar}$ analysis of potassium-manganese oxides. Science 1992, 258:45I-455.

46. Marroig G, Cropp S, Cheverud JM: Systematics and evolution of the Jacchus group of marmosets (Platyrrhini). Am J Phys Anthropol 2004, I 23: I I-22.

47. Carnaval AC, Hickerson MJ, Haddad CF, Rodrigues MT, Moritz C: Stability predicts genetic diversity in the Brazilian Atlantic forest hotspot. Science 2009, 323:785-789.

48. Pedro PM, Sallum MA, Butlin RK: Forest-obligate Sabethes mosquitoes suggest palaeoecological perturbations. Heredity 2008, 10I: 186-95.

49. Nei M, Kumar S: Molecular Evolution and Phylogenetics New York: Oxford University Press; 2000

Publish with Bio Med Central and every scientist can read your work free of charge

"BioMed Central will be the most significant development for disseminating the results of biomedical research in our lifetime. "

Sir Paul Nurse, Cancer Research UK

Your research papers will be:

- available free of charge to the entire biomedical community

- peer reviewed and published immediately upon acceptance

- cited in PubMed and archived on PubMed Central

- yours - you keep the copyright
BioMedcentral 